\title{
APRENDIZAGEM CONTESTADA EM AMBIENTE DE MUDANÇA RADICAL
}

\section{RESUMO}

Este artigo oferece uma anál ise da aprendizagem nas organizações em condições de mudança radical, em que a reestruturação da organização foi motivada por uma mudança na ideologia e na propriedade. Discute-se que, nessas circunstâncias, a aprendizagem não representa necessariamente uma melhoria para o coletivo como um todo. A fonte empírica para este artigo é um estudo de caso da Telemig, uma das principais companhias brasileiras de telecomunicações. A pesquisa empregou múltiplos métodos e fontes permitindo uma investigação do conteúdo e do processo de aprendizagem, e de seus agentes ao longo do tempo. 0 estudo elabora eilustra o conceito de "aprendizagem contestada", concluindo que este necessita ser incorporado à teoria da aprendizagem nas organizações.

\section{Suzana B. Rodrigues}

Cepead-UFM G e Birmingham University

\section{John Child}

Birmingham University

\section{Talita R. Luz}

Cepead-UFM e Faculdade Novos Horizontes

\begin{abstract}
This paper offers an analysis of learning in organizations in conditions of radical change, in which organization restructuring was motivated by a change in ideology and owner ship. It is argued that in these conditions learning does not necessarily represent an improvement to the collective as a whole. The empirical source for this paper is a case study of Telemig, a major Brazilian telecommunications company. The research employed the multiple methods and sources. This approach permitted an investigation of the content and process of learning, and its agents over time. The present study elaborates and illustrates the concept of 'contested learning'. It concludes that this concept needs to be incorporated into the theory of learning in organizations.
\end{abstract}

PALAVRAS-CHAVE Aprendizagem nas organizações, aprendizagem contestada, mudança radical. KEY WORDS Learning in organizations, contested learning, radical change. 


\section{INTRODUÇÃO}

0 tema da aprendizagem em organizações tem recebido bastante atenção na teoria, principalmente sob a perspectiva sócio-psicológica. É tratado como um fenômeno cognitivo e técnico, em contextos de equipes cooperativas, associado geralmente à geração e à difusão de novos conhecimentos e de competências nas organizações. Essa abordagem fez avançar nossa compreensão de como a aprendizagem é socialmente construída (Weick, 1995; Gherardi e Nicolini, 2001; Corley e Gioia, 2003), mas não deu muita atenção a como a aprendizagem pode ser motivada por interesses seccionais em contextos de mudança política e organizacional. Embora al guma atenção tenha sido dadaà associação en trea aprendizagem organizacional e a mudança organizacional em geral (por exemplo, Von Rosenstiel e Koch, 2001), somente alguns estudos foram mais fundo (Merkens et al., 2001; LaPalombara, 2001) em explicar como as organizações absorvem as visões e opiniões que são imbuídas ideológica e institucionalmente e as transformam em práticas e rotinas.

Argumentou-se que as organizações são impregnadas de ideologia (Simons e Ingram, 1997). Contudo, é pouco compreendido como as organizações importam e aplicam a ideologia. Os estudos sobre o controle administrativo e a subjetividade no lugar de trabalho trouxeram os temas de ideologia e aprendizagem à atenção (Knights e Willmott, 1987; Alvesson e Willmott, 2002), mas com pouca referência à influência potencial do ambiente institucional. Os estudos de aprendizagem investigaram intensivamente os processos cognitivos, como as organizações incorporam modelos de mundo, atitudes e comportamentos (March e Simon, 1958; March e Olson, 1976). Demonstraram, também, como a aprendizagem afeta os significados intersubjetivos e a identidade (Corley e Gioia, 2003; Gherardi e Nicolini, 2001; Child e Heavens, 2001).

Entretanto, essas contribuições não investigaram como a ideologia pode associar as identidades das organizações e dos indivíduos às relações de poder por meio dos processos de aprendizagem.

Fear (2002, p. 183) discutiu que as teorias sobre aprendizagem necessitam da contribuição de abordagens históricas, capazes de lançar luz sobre os tipos de valores que os administradores evocam a fim de mudar a estratégia. Ele defende a análise do impacto de "pontos cruciais no instante em que as formas precedentes de raciocínio legitimado abrem caminho para novas formas". A pesar dessas reivindicações, os estudos organizacionais em geral vêem a ideologia como uma força invariável e dada. Existem os períodos em que a ideologia se torna uma força muito poderosa de transformação nas organizações, incentivando mudança na mentalidade, na estrutura ou em ambas (Child, 2000).

Os eventos ideológicos criam a base para mudanças de propriedade ou mudanças estruturais, que requerem a adaptação nos significados, nas inter-relações e nas interações dentro das organizações. Impõem novas demandas aos administradores e empregados e levantam, conseqüentemente, a necessidade de reinventar, inovando e aprendendo. Essas demandas, por sua vez, criam a necessidade de teorias que facilitem sua implementação. A ideologia e a propriedade são de fato forças complementares no sentido de que a primeira reflete os interesses da última. A ideologia fornece a justificação simbólica que explica e legitima os direitos de propriedade para substituir regras explícitas eimplícitas que afiançam contratos sociais nas organizações.

Este artigo oferece uma análise da aprendizagem nas organizações em condições de mudança radical, em que a reestruturação da organização foi motivada por uma mudança na ideologia e na propriedade. Discute-se que, nessas circunstâncias, a aprendizagem não representa necessariamente uma melhoria para o coletivo como um todo. A ruptura de confiança que freqüentemente acompanha mudanças de propriedade pode privar a aprendizagem de seu elemento essencial, a motivação (Blair, 1995; Child e Rodrigues, 2003a). Osindivíduos provavel mente resistem à aprendizagem quando percebem que ela ameaça a identidade e seus interesses (Brown e Stakey, 2002, p. 102). Assim, o artigo levanta a questão se a aprendizagem, apoiando-se em ideologias que legitimam os arranjos estruturais dados - tais como o downsizing - pode mitigar seus impactos políticos sobre o coletivo. Contribui para o conhecimento, mostrando que aprendizagem não é um fenômeno técnico neutro, mas podetambém expressar e servir a finalidades políticas.

0 artigo baseia-se em uma história de dez anos de um estudo de caso em profundidade de uma companhia brasileira de tel ecomunicações, a Telemig. Analisa como uma organização no setor de tel ecomunicações incorpora idéias e práticas neoliberais à sua cultura corporativa no processo de mudança de estatal para privada. Aprender "os significados do mercado" foi considerado a base principal sobre a qual uma organização nova poderia ser construída, fornecendo também a justificação para a reestruturação que ocorreu.

Neste artigo analisamos as intenções dos administradores e a reação correspondente dos empregados ao programa de aprendizagem, seguida de mudança de propriedade privatização - e de reestruturação da organização. 0 estudo de caso ilustra como a reestruturação radical foi iniciada em bases ideológicas, mas tornou-se contraprodutiva por- 
que alienava os empregados. Mostra como as mudanças, antes e depois da privatização, envolveram a aprendizagem de val ores e competências que eram compatíveis com empresas privadas e com a ideologia neoliberal.

Começamos com uma perspectiva teórica que discute os princípios do neo-liberalismo, e como ele envolve expectativas consistentes sobre o papel dos indivíduos na sociedade e prescrições sobre como os indi víduos devem, em geral, relacionar-se com seu trabalho e sua organização. Mostraremos como o tipo de reestruturação que aconteceu no caso estudado e como o tipo de competências enfatizadas pela administração espel hou concepções ideológicas no nível macro da economia política. 0 caso a ser discutido ilustra como as definições neoliberais de bens econômicos estavam refletidas no que foi definido como aprendizagem organizacional apropriada. Enquanto alguns aceitaram as definições novas como um fato, para muitos outros aprender as "vias do mercado" conduziu a uma ruptura de confiança difícil de reparar.

\section{PERSPECTIVA TEÓRICA: APRENDIZAGEM COMO EMPREENDIMENTO POLÍTICO}

A aprendizagem e a criação do conhecimento organizacional foram consideradas como conducentes ao "desenvolvimento" e à "inovação". Ou seja, foram associadas com a passagem de uma capacidade menos sofisticada a um patamar superior, a habilidades complexas, a um estágio avançado, que realçasse o repertório comportamental das pessoas e mel horasse a capacidade de encontrar soluções para os problemas (Skinner, 1974; Sutherland, 1992). Assim, a aprendizagem foi geralmente concebida como uma coisa positiva, ou emancipatória (Fiol eLyles, 1985; Senge 1997). $\mathrm{N}$ essa perspectiva presume-se que a aprendizagem beneficia a todos os empregados, uma das razões pelas quais seu papel como agente do processo foi percebido como tranqüilo. Do mesmo modo, a aprendizagem pelos membros da organização deve ser compartilhada para se transformar em uma propriedade da organização - convertendo conhecimento tácito em explícito (Nonaka e Takeuchi, 1995).

Essa perspectiva benigna de "doçura e de luz" ignora conflitos de interesse entre a administração e os empregados, e a possibilidade de que a aprendizagem organizacional possa se tornar serva das políticas que não são de interesse coletivo (Knights e Willmott, 1989; Alvesson e Willmott, 1996). U ma conseqüência é que a aprendizagem organizacional ésempre mais sujeita a criar uma ruptura de confiança entre a administração e os empregados do que reforçar a confiança entre eles.
Perspectivas diferentes destacam dimensões distintivas desse problema. Os estudos de governança da propriedade e do controle, assim como estudos organizacionais sobre administração e controle, indicam que os administradores podem ser politicamente comprometidos com uma concepção do papel de outros stakeholders que não considera as expectativas e necessidades dos empregados. Blair (1995; 1996) sugere que algumas estratégias administrativas que conduzem à reestruturação organizacional tendem a transferir a riqueza para os acionistas à custa dos empregados. Os estudos de administração e control e indicam que as estratégias de aprendizagem podem ser uma arma poderosa de mudança da organização, a serviço do interesse da coalizão dominante. Os administradores podem avançar suas idéias por meio de diferentes meios, tais como programas educacionais, reestruturação da organização, ou de maneiras mais sutis, como criação de uma nova cultura da organização. A literatura em estudos da organização forneceu evidências abundantes sobre como os administradores usam a cultura organizacional como um mecanismo para controlar empregados e conseguir seus objetivos (Child, 1984; Collinson, 1992; Thompson e Mchugh, 2002; Rodrigues, 2003). A aprendizagem pode ser uma arma poderosa da mudança, desde que possa ser usada para estimular o desenvolvimento da orientação para o trabalho e "identidades do trabal ho" que são congruentes com os objetivos dos administradores (Alvesson eW illmott, 2002, p. 622). Esses autores sugerem que controlar a identidade dos trabalhadores transformou-se em uma ferramenta crítica para os administradores porque pode ajudar os empregados a aceitar mudanças hostis, tais como reestruturação e downsizing.

A mudança ambiental acarreta o reposicionamento ideológico das coalizões dominantes com conseqüências para o tipo de demandas institucionais que repercutem nas organizações. A mudança de governos, por exemplo, pode exercer pressão para mudanças de propriedade e de controle, especialmente por meio da privatização, quetende a desencadear novas políticas organizacionais com implicações para as formas e a identidade da organização (Rodrigues eChild, 2003a). Desse modo, a ideologia política tem impacto nas organizações por meio de decisões sobre formas de organização - hierarquia e estrutura - e estratégia (Simons e Ingram, 1997).

A ideologia, porém, não ésimplesmente uma força autônoma, exógena. Administradores adotam-na e trazem-na para as organizações como uma explicação para apoiar ações tais como os programas de aprendizagem. Estes podem ser condutos ideais da ideologia na medida em que incorporam idéias sobre formas e estratégias organizacionais e definem também o lugar que é reservado para o empregado na 
organização. Tais expectativas al cançam os empregados de uma maneira sutil, como, por exemplo, por meio da cultura corporativa. Os administradores articulam e canalizam a cultura corporativa para suprir os trabal hadores com valores fortes (Ray, 1986; Pettigrew, 1979; 1987). A reestruturação que conduz a mudanças no contrato social com os empregados pode ser apresentada positivamente como um "modo mais avançado de organizar ou de dar poderes" (Kelly, 1996). Se implementada corretamente, a aprendizagem conduz à internalização dos valores e das normas.

A literatura sobre aprendizagem organizacional e aprendizagem nas organizações pode sugerir o tipo de valores que as organizações do livre mercado podem inculcar. Um dos conceitos-chave é o de adquirir competências ( $D 0 z$, 1997). Desenvolver competências centrais significa fazer o que outros não poderiam fazer (Prahalad e Hamel, 1990). $\mathrm{Na}$ medida em que as competências centrais representam adição de valor, as empresas têm sido encorajadas a eliminar pessoas e atividades deficitárias (Cascio, 2002). 0 conceito de competência central trouxe consigo o modelo de estruturas enxutas e médias, e a necessidade de remodelar a qualidade dos administradores e dos empregados de modo congruente com a construção das competências-chave das organizações (Doz, 1997).

A análise das teorias de aprendizagem organizacional revela o tom ideológico dos conceitos que elas incorporam. Sugere que 0 desenvolvimento de novas competências depende da capacidade das organizações em articular competências individuais às estratégias. Su põe-seque as competências estratégicas podem somente ser adquiridas quando a organização associar a cognição e o comportamento com um certo tipo de mentalidade (Doz, 1997). 0 "saber ser" (LevyLeboyer, 1993) - atitudes e val ores (Bartlett e Goshal, 1997) - é visto como a possível ligação entre o comportamento individual ea aprendizagem coletiva com as competências que a organização pretende adquirir. Em contraste ao conceito de habilidades que foi referido como conhecimento tácito, 0 conceito de competências implica também a externalização de valores internalizados que se refletem na capacidade de adaptação dos indivíduos. Refere-se às habilidades que são aplicáveis aos contextos particulares, com a flexibilidade re presentando um papel-chave (Levy-Leboyer, 1993).

Quando um programa de aprendizagem é aplicado para conectar o conhecimento, as habilidades e as competências da organização com as visões que são articuladas externa e institucionalmente, cessa de ser um dispositivo educacional (Skinner, 1974) e transforma-se em um instrumento político que une programas no nível institucional às capacidades auto-regulatórias dos indivíduos (Rose, 1992). Isso demonstra como os administradores podem ser agentes para implementar as idéias concebidas no nível macro, e também mostra o papel da ideologia em reconciliar a subjetividade individual às aspirações institucionais.

\section{0 papel da ideologia: neoliberalismo como motivação e conteúdo para aprender}

0 liberalismo foi a ideologia mais importante elaborada na sociedade ocidental desde o século XIX atéa Primeira Grande Guerra. Embora tivesse seguidores nos Estados Unidos e no Reino Unido e tenha sido rearticulado nos anos 1940 como um antídoto ao totalitarismo por autores como Von Hayek (1960) ePopper (1962), tornou-se ressurgente como uma força global somente pelo começo dos anos 1990. Nesse tempo, os governos de economias emergentes criaram um ambiente político e econômico - abrindo seus mercados à competição internacional e perseguindo a privatização que permitiu a transferência de suas idéias às organizações e a seus membros.

0 neoliberalismo transmite idéias que são relevantes para o tema deste artigo de três maneiras: sobre a propriedade, sobre o livre mercado e sobre o individualismo. De fato, sua influência deriva de sua capacidade de ligar concepções sobre as instituições - o mercado como uma instituição -, as organizações - competitividade - e a autoconfiança individual. No Reino Unido essas idéias foram transmitidas às organizações e aos indivíduos por meio da idéia, de Margaret Thatcher, de "cultura empresarial" (Hellas e M orris, 1992). Envolveram criar um livre mercado, reduzindo o poder do Estado e devolvendo-o aos indivíduos e às famílias. Estava-se preocupado em expandir as forças de mercado de modo que as pessoas aumentassem sua autonomia como consumidores e como indivíduos na sociedade. Nessa concepção, os indivíduos devem seliberar do Estado imperativo e partir para o autodesenvolvimento. As pessoas deveriam confiar em seus próprios recursos para competir no livre mercado e usar a riqueza que criaram para investir em suas próprias potencialidades e necessidades, como em saúde e educação. A autoconfiança deveria dotá-las de auto-respeito.

A interferência do Estado era, portanto, concebida como um impedimento à eficiência organizacional e à realização individual. As organizações do Estado foram vistas como vilãs (Carrier, 1997); eram responsabilizadas por falhas econômicas assim como por constranger a liberdade das organizações e dos indivíduos. 0 mercado é meIhor do que o Estado para coordenar a produção e a distribuição dos produtos e serviços, tanto moralmente em termos da distribuição da riqueza, quanto em eficiência (Hayek, 1960; Friedman, 1962). As organizações privadas são consideradas a unidade econômica ideal porque se apóiam 
em uma estrutura de propriedade que as dota das características-chave essenciais para o sucesso de mercado, tais como a flexibilidade em mover suas atividades para onde for mais vantajoso earranjos contratuais flexíveis para ajustar suas operações de modo que maximizem a riqueza.

A empresa ideal ofereceu um modelo ético para as organizações em que a ênfase deve ser colocada na soberania do cliente e da competição. A lógica é a da sobrevivência do mais apto: as empresas devem lutar com "competitividade, força, vigor, agressividade e o impulso para obter sucesso" (Rose, 1992, p. 149). A cultura da empresa importou de Schumpter a atenção à inovação, enfatizando a visão e a imaginação. Realçou virtudes gerenciais com ênfase na eficiência e a relevância do risco pela atenção aos lucros (Marquand, 1992). Não é surpreendente que idéias sobre vantagem competitiva, organização de conhecimento ecompetências centrais se transformem nos paradigmas principais na estratégia administrativa dos anos 1990.

No neoliberalismo, o tipo ideal de empresa é caracterizado pela aprendizagem do indivíduo e da organização. Supõe-se, paradoxalmente, quetanto as organizações como os indivíduos podem aprender a ser o que o governo espera deles. Como Rose (1992, p. 150) argumenta, "o empreendedor é assim um ser calculista, uma pessoa que calcula sobre si mesma equetrabal ha a fim de semelhorar". Hellas e Morris (1992) criticaram a cultura da empresa por sua suposição de que os indivíduos devem aprender o que governos neoliberais supõem que seja apropriado para eles.

A cultura da empresa foi baseada na suposição neoclássica de que o auto-interesse é o estímulo que motiva o comportamento humano. Em suas publicações, Friedman (1960) e Von Hayek (1960) sugerem que o bem-estar dos indivíduos pode ser conseguido se eles puderem criar sua própria riqueza participando livremente de atividades do mercado. 0 Estado restringe não somente a racionalidade individual, mas cria também a dependência. A nova ordem moral envolveu 0 aniquilamento das políticas sociais que incentivam a dependência e a acomodação.

0 neoliberalismo, conseqüentemente, fornece idéias claras sobre 0 tipo de organizações e de empregados que são ideais para o livre mercado. Os governos esperam que a administração examine esses preceitos eos execute em suas organizações. Isso deveser feito por meio da criação de novas competências pelas organizações e dentro delas (Rose, 1992; De Marquand, 1992). Porque a aprendizagem lida com significados intersubjetivos (Coley e Giogia, 2003), pode ser usada como um instrumento político capaz de articular concepções das organizações e de seus empregados, que são aliadas aos objetivos políticos de coalizões dominantes. N esse caso, a aprendizagem transforma-se em uma tecno- logia do próprio ser, dando forma não somente a aspectos da vida privada, mas afetando também a identidade dos indivíduos, como Rose (1992) argumenta.

Por outro lado, pode-se afirmar que os atores não são seres passivos sujeitos às forças externas ou à vontade administrativa (Littler, 1982; Alvesson e Willmott, 2002). A aprendizagem ésocial, no sentido de que sua externalização por meio do comportamento está intimamente ligada à internalização de val ores (Berger e Luckmann, 1966); tem um aspecto comportamental ecognitivo (Fiol eLyles, 1985). A aprendizagem socialmente construída pode ocorrer com a interação social e independentemente da administração.

As pessoas gozam também de certo grau de autonomia pessoal. Conseqüentemente, a aprendizagem igualmente constitui um campo de engajamento político e social em que os atores são informados cognitivamente pelo passado - suas experiências anteriores no trabalho -, pelo presente - sua capacidade de contextualizar a experiência passada e por projetos em andamento dentro das contingências do momento - e são orientados também pelo futuro - sua capacidade de visualizar alternativas. Nas situações em que a mudança é compulsória - "aprender ou perecer" -, isso pode causar o surgimento da aprendizagem contestada.

A aprendizagem contestada refere-se às disputas a respeito de sua legitimidade. Envolve o conflito existente sobre a eqüidade entre as contribuições e os benefícios, incluindo a distribuição do retorno entre as partes interessadas - stakeholders - e grupos ocupacionais diferentes (Child e Loveridge, 1990). Nessa situação, a organização pode ser incapaz de construir os significados intersubjetivos que são congruentes com a identidade projetada da organização (Corley e Giogia, 2003). Como Brown e Starkey (2000) indicam, os participantes podem se recusar a aprender o que ameaça a imagem ideal izada da organização e, conseqüentemente, o que aumenta seu receio pela integridade de sua própria identidade. Em vez do incentivo à emancipação, a aprendizagem cria mais insegurança e frustração no que concerne ao futuro. Os empregados podem descobrir que as mudanças, que eram supostamente positivas, trazem uma ruptura em seu contrato social implícito com a administração.

Uma ruptura do contrato social pode ser sentida ao longo das dimensões cognitivas, emocionais e econômicas. Reflete o ressentimento que surge ao comparar como era a organização com o que é agora, em termos dos elementos que afetam a identidade dos empregados. A situação nova pode representar a redução do status, privação financeira e escolha restrita. Essa escol ha pode estar entre a adaptação /resistência ou a saída. Na primeira delas, os emprega- 
dos incorporam o discurso administrativo sem acreditar nele; na segunda, podem optar por uma aposentadoria precoce ou encontrar um outro trabalho. Se se sentirem presos em um sistema organizacional com o qual não concordam, tornam-se apáticos ou opõem-se aberta ou tacitamente à mudança.

\section{Aprendizagem e ruptura de confiança}

Embora tenhamos afirmado que a aprendizagem pode ser uma arma poderosa para a mudança organizacional, há já evidências abundantes na literatura de que mudanças recentes introduzidas por organizações podem conduzir à alienação e estender o conflito entre a administração e os empregados de manei ra a poder reverter os objetivos da aprendizagem. Quando o investimento na aprendizagem sucede a mudanças na propriedade ou a aquisições, é acompanhado geralmentede reestruturação (Bowman et al., 1999; Blair, 1995; 1996; Weston et al., 2001). Tal reestruturação, especialmente quando acompanhada pelo downsizing, causa freqüentemente uma quebra na confiança, com a aprendizagem conseqüentemente tornando-se contestada entre vencedores e perdedores no processo de reestruturação (Littler 2000). Em alguns casos, como quando as companhias estão sendo preparadas para a privatização, a reestruturação pode preceder à mudança da propriedade. Em outros casos, quando a reestruturação segue à mudança da propriedade, a nova administração provavelmente não se sente comprometida com os contratos estabel ecidos pela administração anterior, o que provoca uma ruptura da confiança entre empregadores e empregados (Blair, 1996; Shleifer e Summers, 1988; Blair, 1995; Deakin et al., 2003; Child e Rodrigues, 2003). A nova administração declara que não tem uma obrigação "moral" em manter os contratos implícitos feitos por administradores precedentes. Esseargumento da ruptura da confiança é revelado pelos estudos de reestruturação de empresas, que indicam como foram beneficiados os acionistas e a alta administração à custa dos empregados (Blair, 1995; 1996; Shleifer e Summers, 1988).

Essa al egação encontra abrigo na perspectiva econômica que vêa organização simplesmente como um nexo de contratos. Blair (1995) e outros discutiram que, se a organização for compreendida nos termos de um grupo de contratos, é impossível especificar cada caso em que pode ocorrer uma ruptura do contrato social em relações de emprego. Isso se dá porque muitas das expectativas mútuas entre empregados e empregadores permanecem na maioria das vezes implícitas. Conseqüentemente, quando os empregados investem em treinamento e aprendizagem, que os provêm com as habilidades compatíveis ao desenvolvimento de vantagens específicas da empresa, eles tendem a esperar que os administradores retribuam, fornecendo-Ihes emprego, segurança e pensões.

Há indicações de que os empregados que buscam novos trabalhos perdem entre $15 \%$ e $20 \%$ nos salários, além do valor dos benefícios (Osterman, 1999). Child e Rodrigues (2003) sugerem que as companhias podem tratar do problema apertando seus controles hierárquicos, pelo emprego de sistemas mais apurados de contabilidade, e monitorando a tecnologia de informação.

\section{METODOLOGIA}

A fonte empírica para este artigo é um estudo de caso da Telemig, uma das principais companhias brasileiras de telecomunicações. A pesquisa empregou múltiplos métodos e fontes listados no Quadro 1, a saber: entrevistas, questionários, documentos ejornais. Essa abordagem permitiu uma investigação do conteúdo e do processo de aprendizagem, e de seus agentes ao longo dos tempos. Essa pesquisa em particular é baseada em dados extraídos de oito anos de história da companhia, entre 1993 e 2000, inclusive. É parte de um estudo mais amplo que investiga a co-evolução, a cultura e a identidade da empresa, incluindo 27 anos da história da companhia (Rodrigues e Child, 2003a; 2003b; Rodrigues, 2003). 0 Quadro 1 resume os métodos de pesquisa usados, cobrindo toda a história da empresa. Este artigo baseia-se nos dados coletados a partir de 1997.

As entrevistas incluíram perguntas sobre a história da companhia, a reestruturação da propriedade, as mudanças na cultura corporativa ena identidade, eo processo de aprendizagem. 0 questionário mediu as competências organizacionais e individuais percebidas por quatro categorias da equipe de funcionários: diretores, gerentes, coordenadores e supervisores.

\section{O ESTUDO DE CASO}

\section{Um resumo da história da Telemig}

A Telemig foi fundada em 1953 como uma companhia privada, parte de um grupo canadense. Em 1973, el a foi incorporada à Tel ebrás, a holding brasileira estatal que controlava a maioria das operações de telecomunicações do Brasil. 0 governo era o maior acionista, mas a Telemig teve também acionistas minoritários entre cidadãos brasileiros. Como uma companhia do Estado, seu ambiente foi altamente protegido. Desde que a holding do Estado foi criada sob o governo militar, não foi permitido às companhias estrangeiras entrarem no mercado das telecomunicações, exceto na 
indústria de manufatura de equipamentos. Praticamente cada Estado da Federação brasileira teve sua própria companhia de telecomunicações, e el as não competiam entresi. Inicialmente, a maioria dos recursos para a expansão das telecomunicações veio do governo e dos bancos internacionais. Obter lucros e ser auto-suficiente somente se transformou em um problema no começo dos anos 1980, quando os fundos dos governos para as telecomunicações começaram a desvanecer. Até os anos 1990, as empresas de telecomunicações tinham uma missão social e econômica. Quando a Telemig foi criada, a missão das companhias envolveu levar as comunicações para o interior e para os locais peque nos, integrá-los à vida urbana e estimular seu desenvolvimento econômico. Mesmo quando essa missão foi considerada concluída, a Telemig manteve um ethos de responsabilidade social com o desenvolvimento econômico e o bem-estar de comunidades locais. Por causa disso, seus empregados eram altamente considerados em suas comunidades.

Esperava-se que eles contribuíssem para a integração social e política do país e para o crescimento econômico nacional. Assim, a Telemig teve um departamento de pesquisa e de desenvolvimento que introduzia inovações importantes nas telecomunicações brasileiras. 0 departamento de engenharia foi considerado o principal condutor da organização; esperava-se que todos os demais departamentos seguissem as prioridades estabelecidas por ele. Os engenheiros eram considerados uma elite poderosa na Telemig.

Durante sua vida como empresa estatal, a Telemig teve a reputação de ser uma das mel hores companhias telefônicas do país, bem conceituada por causa das inovações tecnológicas que tinha introduzido nas telecomunicações. Considerava-se que ela tinha os melhores engenheiros, era meIhor administrada e fornecia boa qualidade nos serviços. Por causa da boa reputação no Brasil, os empregados da Telemig eram freqüentemente convidados a fornecer consultoria e treinamento para outras companhias do grupo Telebrás. Os empregados das companhias estatais apreciavam a segurança no emprego; demissões ocorriam, mas somente sob circunstâncias especiais. A cultura da companhia foi baseada em uma burocracia técnica, que mitigava

Quadro 1 - Métodos de pesquisa e fontes em três fases da investigação.

\begin{tabular}{|c|c|c|}
\hline FASE I: 1986-1990 & FASE II: 1997-2000 & FASE III: 2001 \\
\hline $\begin{array}{l}\text { Telebrás (empresa holding) } \\
\text { Dossiês: } \\
\text { - } 25 \text { biografias de heróis e líderes do } \\
\text { setor de telecomunicações brasileiro } \\
\text { Entrevistas: } \\
\text { - } 5 \text { executivos seniores } \\
\text { - } 4 \text { empregados aposentados } \\
\text { - Antigo funcionário do Ministério das } \\
\text { Comunicações no Brasil (1976-1990) }\end{array}$ & & $\begin{array}{l}\text { Telebrás (empresa holding) } \\
\text { Documentos: } \\
\text { - } 144 \text { documentos das políticas e práti- } \\
\text { cas da Telebrás (1973-2000) } \\
\text { - } 10 \text { documentos da Anatel (agência re- } \\
\text { guladora) }\end{array}$ \\
\hline $\begin{array}{l}\text { Telemig (companhia focal) } \\
\text { Entrevistas: } \\
\text { - } 5 \text { diretores } \\
\text { - } 60 \text { administradores e engenheiros em } \\
\text { divisões, departamentos, e nível de } \\
\text { setor } \\
\text { - } 4 \text { funcionários locais do sindicato } \\
\text { Documentos: } \\
\text { - Análise de } 304 \text { cartoons no jornal } \\
\text { do Sindicato (0 Bode) } \\
\text { (1979-1990) } \\
\text { Outros: } \\
\text { - Consultor de Desenvolvimento Adminis- } \\
\text { trativo da Telemig } \\
\text { - Funcionário do Fittel (Sindicato Nacio- } \\
\text { nal das Telecomunicações) }\end{array}$ & $\begin{array}{l}\text { Telemig (companhia focal) } \\
\text { Entrevistas: } \\
\text { - } 4 \text { diretores } \\
\text { - } 2 \text { ex-presidentes } \\
\text { - } 45 \text { administradores em nível de gerên- } \\
\text { cia, divisão e seção } \\
\text { - } 40 \text { técnicos (engenheiros, supervisores, } \\
\text { cabistas, telefonistas) } \\
\text { - } 8 \text { empregados aposentados } \\
\text { Questionários: } \\
\text { - } 52 \text { respondentes: diretores, gerentes, } \\
\quad \text { supervisores, empregados } \\
\text { Documentos: } \\
\text { - Análise de } 200 \text { cartoons no jornal do } \\
\text { Sindicato (0 Bode e 0 Bodim) } \\
\text { (1990-2000) }\end{array}$ & $\begin{array}{l}\text { Telemig (companhia focal) } \\
\text { Documentos: } \\
\text { - Relatónios da Companhia (1973-2000) } \\
\text { - Organogramas (1983-2000) } \\
\text { - } 130 \text { edições dos jornais do Sindicato } \\
\text { (O Bode e O Bodim) e outros boletins } \\
(1990-2000)\end{array}$ \\
\hline
\end{tabular}


os efeitos da elevada distância hierárquica entre os superiores e os subordinados por meio do fortalecimento de uma cultura fundada em paternalismo benevolente.

A identidade da Telemig foi ameaçada quando o governo brasilei ro começou a sinalizar para a necessidade de privatização das empresas estatais, sendo as telecomunicações consideradas uma prioridade. A Telemig começou a se preparar para a privatização em 1993, e foi privatizada realmente em 1998. Entre esses anos, a companhia começou a experimentar uma série de ações de preparação para a privatização, que conduziram à quebra de laços institucionais e, final mente, à destruição de sua identidade. De 1993 em diante, a organização foi envolvida em um processo deaprendizagem que objetivava a criação de uma mudança de mentalidade que permitisse adquirir as virtudes de uma "organização do mercado", em um primeiro instante, e, então, aquelas de uma firma de propriedade privada. Isso a tornaria atrativa ao capital privado estrangeiro enacional. 0 processo de aprendizagem que vamos descrever abaixo referese aos processos que conduziram a Telemig a uma mudança da identidade e ao desenvolvimento de competências organizacionais e individuais.

\section{O PROCESSO DE APRENDIZAGEM}

\section{Neoliberalismo como ideologia diretiva}

No início dos anos 1990 tornou-se evidente que o modelo brasileiro de desenvolvimento baseado na intervenção do Estado não se enquadrava nas expectativas econômicas e sociais. 0 governo que assumiu em 1993 começou a expressar sua preferência por um arcabouço neoliberal, explicitando uma mensagem que ideal izava as virtudes "do mercado" ao contrário das deficiências "do Estado" (Carrier, 1997). As idéias liberais foram transmitidas às organizações por ministros, funcionários e políticos nos partidos do governo (Boschi et al., 2000).

No setor de telecomunicações foi a conexão entre o Ministro das Comunicações e a al ta administração que facilitou a execução da privatização (Pires, 1999). A Telemig teve dois tipos de presidentes após 1993: aqueles que tinham construído sua carreira dentro da companhia, eos políticos que adotaram o ideário neoliberal. 0 papel desse presidente era o detransformar a companhia estatal para fazê-la atrativa aos investidores privados em um futuro próximo. Esperava-se que os dois presidentes que precederam imediatamenteà privatização preparassem o terreno paraa construção de uma nova identidade para a Telemig, o que envolveu mudar de uma tecnocracia para uma organização de mercado (Rodrigues e Child, 2003b).

\section{Mudança de propriedade e reestruturação}

Por volta de 1993, os empregados já sabiam que a companhia seria privatizada em um futuro próximo. A perspectiva de uma abordagem neo-liberal à economia incentivou a mudança de empresa de engenharia para fornecedora de serviços. A fim de dar suporteà mudança para uma companhia fornecedora de serviços, a Telemig aumentou seu investimento em treinamento junto com um programa de aposentadoria incentivada. A mensagem contida nesse desenvolvimento era a necessidade de transformar a companhia em uma organização mais pró-ativa e de ação mais rápida, que possuísse um conhecimento detal hado do mercado das telecomunicações. Termos como criatividade, flexibilidade, motivação e otimização se tornaram parte do vocabulário da companhia. 0 axioma mais importante era que "o cliente está sempre certo" (Luz 2001; Carrieri, 2001). No documento da empresa, "Construindo a Transformação" (1995), a administração declarou que:

"a companhia quebrou os paradigmas tradicionais dando a primazia ao cliente, e construindo alianças estratégicas. Promoveu uma mudança da mentalidade, a fim preparar-se para a competição".

Este período representa conseqüentemente a mudança do velho paradigma tecnoburocrático para outro focalizado no mercado. Seus programas de desenvolvimento da administração visavam construir as competências necessárias para tirar a empresa da dependência do Estado e assegurar recursos do mercado.

Em 1995, quando o plano de privatização do governo passou primeiramenteno Congresso, a Telemig empreendeu uma grande reestruturação em que engenharia e operações foram separadas das áreas comerciais. A companhia criou unidades de negócio e um departamento de marketing. A unidade de serviços foi subdividida em outras quatro sub-unidades que cobriam áreas de celulares, grandes clientes, as áreas metropolitana e rurais. 0 foco da companhia tornou-se claramente definido. As operações agora tinham que trabalhar sob a orientação das unidades denegócio. A intenção era mudar de uma companhia sem diferenciação entre clientes para diferenciação por segmento demercado; de uma companhia deengenharia para uma empresa integrada. Neste período, a Telemig mudou também seu logotipo para representar sua nova identidade. A empresa definiu seus objetivos estratégicos: aproximar-se do mercado de uma maneira estratificada e lucrativa, identificando as necessidades dos clientes em termos de localidade, de tempo, de preço e de qualidade superior; ser a líder demercado na tel efonia móvel, maximizar a produtividade da planta, e investir em infra-estrutura de capacidade elevada. 
A fim de atingir estes objetivos, a companhia desenvolveu uma série de novos serviços que criaram soluções específicas para clientes, com os custos mais baixos e maior valor agregado. Em fevereiro de 1998, o negócio de tel efonia móvel foi transformado em uma companhia independente, e 107 empregados deixaram a empresa em um programa de aposentadoria incentivada.

Em 22 maio de 1998, a Telemig, junto com outras 15 operadoras do N orte, do N ordeste, e Leste do país, tornouse parte da Telemar, que é uma das 12 "holdings" criadas pela dissolução da Telebrás. Seu controle majoritário coube a investidores institucionais nacionais.

Após a privatização, a companhia holding continuou a transformação da Telemig e iniciou uma mudança estrutural mais ampla. 0 novo presidente veio do setor privado. Neste período, 1.059 empregados aderiram ao plano de demissão voluntária ea Telemig terceirizou $37 \%$ de suas atividades. A privatização deu à administração uma maior autonomia para empregar e demitir os empregados. Um dos administradores descreveu aquelas mudanças como "desmontar as velhas estruturas de poder". Trinta e sete cargos gerenciais foram eliminados após a privatização.

A Telemar tinha novos planos para a Telemig, além da mudança de nome. A matriz ficou situada no Rio de Janeiro, uma das áreas de pior desempenho. Como a Telemig era considerada a "jóia da coroa", seus executivos chaves foram transferidos para outras subsidiárias da holding a fim de implantar as melhores práticas, unificar e padronizar o sistema. Na nova estrutura corporativa, a Telemig foi designada como unidade regional, responsável também pela subsidiária de um Estado vizinho. Mas mesmo este poder limitado está agora sob a ameaça de nova reestruturação, em que o papel da Telemig será muito menor, essencialmente um escritório de regional vendas.

Várias decisões, tais como orçamentos, tornaram-se centralizadas no nível da holding. Não obstante, os executivos chaves da hol ding originaram-se da Telemig. Ao transformarse em apenas uma subsidiária, a Telemig perdeu a autonomia e o poder, e o seu nome. Seus executivos principais e profissionais chaves foram alocados a outras empresas membros da companhia hol ding e muitos ocupam posições importantes. A empresa é agora dependente da holding para a redistribuição dos recursos e para a definição de suas políticas e operações. A administração da Telemar segue metas de EBITDA e de maximização de valor para o acionista.

Os custos e as finanças são controlados rigidamente; os empregados têm que seguir os procedimentos que vêm da holding. Há um sistema de responsabilidade administrativa e de contabilidade em toda a organização. A empresa agora não precisa publicar suas contas. Uma cultura da competi- tividade e de empregabilidade está sendo imposta na organização. A atitude da administração é de que aqueles que não podem manter seus empregos somente podem responsabilizar a si mesmos. Uma vez que os grupos de controlee outros acionistas não vieram do setor, a opinião geral na imprensa era de que a Telemar fal haria. Entretanto, os relatórios recentes indicam que a Telemar é a melhor operadora no país. A Telemig é responsável por $80 \%$ das rendas da Telemar, de acordo com entrevistas recentes.

\section{0 conteúdo da aprendizagem e a construção de uma nova identidade da organização}

A aprendizagem que ocorreu a partir de 1993 foi orientada para a incorporação de uma identidade e de uma cultura novas na organização. De 1993 a 1998 a aprendizagem envolveu a construção de uma "organização de mercado" e de 1998 a 2000, focalizou a reconstrução de uma "organização privada", orientada para a maximização de valor para os acionistas. A fim de promover a primeira, os empregados tiveram que aprender o "valor real do mercado". Os extratos das entrevistas com administradores e técnicos sugerem que a aprendizagem requeria habilidades e competências de mercado e atitudes que moldassem novas características pessoais para cada um de maneira compatível. Isto foi efetuado por meio de programas de treinamento, com conferências e palestras dadas por administradores e por diretores, "usando todos os meios de comunicação quea organização tinha", como um de seus diretores declarou. 0 fato de a Telemig ter sido uma organização que val orizava a aprendizagem e que havia investido tradicionalmente em programas de treinamento foi visto como um facilitador da mudança. Como um administrador declarou: "a Telemig deu sempre importância ao treinamento; val orizava o desenvolvimento einvestimento em pessoas. A cultura do treinamento ajudou quando nós tivemos que introduzir as mudanças".

Uma variedade de temas expressava a abordagem dos administradores à aprendizagem. Um diretor sugeriu que os programas de aprendizagem deveriam "envolver tantas pessoas quanto possível", "mostrava quea companhiatinha uma liberdade de escolha", "apresentava a evidência de que as mudanças na Telemig seguiam o que estava acontecendo em todos lugares do mundo". Um outro diretor mencionou 0 uso dos panfletos, das trocas de e-mails, de debates pessoais entre administradores e empregados. "Tivemos vários meios de comunicação com os empregados, mas demos prioridade a um ponto-chave, que era a vinda da abertura do mercado financeiro, como uma razão para a mudança".

Extratos das entrevistas dos diretores e administradores sugerem que a companhia se preparou para a privatização tentando inculcar uma nova mentalidade, que envolvia mu- 
dar a identidade da organização e também dos empregados. Um gerente mencionou o seguinte:

\begin{abstract}
"a Telemig foi considerada pelo grupo da Telebrás como a mais preparada para a privatização. Nós começamos a inculcar uma mental idade nova dentro da organização, aquela da empresa privada. Um dos fatores que contribuiu para isto foi transformar a companhia de engenharia para uma fornecedora de serviço".
\end{abstract}

$\mathrm{N}$ ão somente os administradores, mas também outros empregados reconheceram que a companhia estava atravessando uma mudança radical. Como um técnico declarou "os anos 90 foram o tempo em que a Telemig superou-se em 'quebrar paradigmas"'. Um gerente afirmou que "a Telemig começou sua preparação para a 'visão de mercado' nos anos 90". Isto requereu uma nova maneira de conceber o mercado, o cliente e a competição. Esta mudança foi conseguida usando um "discurso sobre a necessidade de mudar para uma organização muito mais flexível e rápida que foi focalizada no cliente". Ao comparar esta organização nova com a Telemig precedente, um outro administrador mencionou que a "velha Telemig não tinha nenhuma preocupação com os clientes"; "eles eram considerados um fardo"; "a companhia tinha seus olhos fechados para o mercado". De acordo com ele a intenção era "construir uma cultura nova na qual o mercado nos diz o que nós precisamos fazer". A redefinição da competência central da companhia refletiuse no organograma da empresa, em que todas as outras divisões (engenharia, finanças, recursos humanos, administração geral e vice-presidência) tornaram-se subordinadas à divisão de serviços ao cliente.

Os diretores usaram al gumas metáforas para descrever esta nova organização para os empregados. Um dos diretores comparou a Telemig a um "jato que substitui as turbinas durante 0 vôo" para passar a imagem de uma organização rápida e flexível. Outros diretores usaram outras metáforas para comparar a nova com a velha Telemig. Um referiu-se à estrutura de paquiderme da Telemig: a Telemig era "um dinossauro que se transformou em um pássaro", "ela pode agora voar onde quer que haja um ambiente mais favorável". Um outro diretor comparou a Telemig, uma organização estatal, a um cavalo amarrado. "Ela era como um animal que tinha muita energia, mas não podia usá-la". Como indicou, "quando o animal está amarrado ele só pode ter uma visão distorcida do mundo. Era incapaz de ver que havia outros cavalos correndo soltos no campo". De acordo com esse diretor, a Telemig só tornouse completamente livre com a privatização. Só então "ela pôde entender a força de um cavalo que corre livremente e aprender com outros cavalos que já estavam correndo livremente no campo". A capacidade da Telemig para colocar em prática esta imagem idealizada de uma "organização do livre mercado" foi entendida pela administração como um processo de aprendizagem que não poderia ocorrer sem um processo de reeducação.

Os diretores da companhia reconheceram que a construção de uma identidade nova para a Telemig requereu a mudança da "personal idade dos empregados", como um deles disse. Havia um entendimento de que construir esta organização nova envolvia renovar e construir uma conceitual ização compartilhada da identidade dos empregados: a maneira como eles se percebiam e eram percebidos por outros (Taijfel, 1982). A aprendizagem foi vista como uma maneira de preparar os empregados a uma mudança principal que estava ocorrendo, aquela da propriedade do Estado para uma companhia privada. Uma linguagem específica foi u sada no programa da reeducação para neutralizar e justificar seu impacto negativo e iluminar seu lado positivo (Kelly, 1998).

Um conceito central colocado por diretores e administradores era o do "empregado empregável". Isto envolvia a necessidade de aprender e mel horar continuamente. De agora em diante, os empregados devem encontrar maneiras de promover suas competências e habilidades. Quanto mais estas competências forem valorizadas no mercado de trabal ho, maior a possibilidade de manter seu trabalho atual na Telemig ou de encontrar um trabalho em qualquer outro lugar. Esta idéia foi relacionada a do empregado renovável. Isto implicava que os empregados deveriam estar preparados para mudar suas mentes sobre o mundo. $\mathrm{N}$ ão havia nenhum lugar para os empregados que foram acostumados às vel has maneiras de fazer as coisas. Uma outra metáfora empregada pela cultura corporativa foi a da multifuncionalidade. Esperava-se que os empregados se ajustassem às mudanças no trabalho e nos cargos. Este conjunto de expectativas sobre o empregado era de fato benéfico para a administração na medida em que preparava os empregados para o downsizing que devia seguir a privatização. Embora nem os administradores nem os empregados tenham afirmado explicitamente isto, estes extratos sugerem que este era o caso. Assim, uma idéia complementar era a do empregado competitivo. A este respeito um diretor mencionou: "o mundo é criado do conflito. Conseqüentemente, não somente a organização, mas também o empregado deve agora aprender como matar seu concorrente com suas próprias unhas".

Assim, o programa educacional da Telemig apontou finalmente para preparar os empregados para uma mudança de propriedade - de uma organização estatal a privada. 
Isto significou não somenteter novos proprietários, mastambém trabal har para eles. Refletindo sobre os relacionamentos com os empregados, alguns administradores mencionaram que "os empregados val em o que produzem" e que "esperase que eles se comportem como se fossem os proprietários", porque "o que conta hoje em dia é como nós podemos gerar lucros não a contribuição da companhia à sociedade, como no passado". Um técnico comentou que "os administradores estão dizendo sempre aos empregados que vão perder seus empregos se não cumprirem a expectativa da companhia", e que "a empregabilidade do empregado depende de quão eficiente ele é em atingir alvos pré-definidos".

\section{Aprendendo novas competências}

Os Quadros 2 e 3 resumem as competências que se tornaram relevantes com a privatização para a organização e os gerentes (diretores, gerentes, coordenadores, esupervisores). Estas duas tabel as resumem dados das entrevistas. 0 Quadro 2 apresenta as competências da organização vista por empregados em posições diferentes. 0 Quadro 3 descreve as competências que foram consideradas relevantes para 0 desempenho da função particular por seus encarregados respectivos. 0 Quadro 2 mostra que as narrativas dos diretores e gerentes foram reiteradas nos discursos dos coordenadores e supervisores, conduzindo à conclusão de que 0 aprendizado da nova identidade da organização foi razoavelmente bem sucedido. 0 Quadro 2 demonstra também isto, mas sugere ainda um grau de ajuste entre o trabalho e as competências pessoais (como fazer e como ser) e concepções neo-liberais sobre os indivíduos que se posicionam nas organizações.

Um survey de 52 questionários fornece pistas adicionais sobrea aprendizagem individual eorganizacional perseguida pela Telemig após sua privatização em 1998. 0 pessoal respondente é representado por 2 diretores, 11 executivos sênior, 32 gerentes médios e coordenadores, e 7 supervisores. 0 survey, real izado no ano 2000 , pediu que os respondentes avaliassem a natureza e o sentido da mudança que tinha ocorrido em aspectos diferentes da aprendizagem edas competências desde a privatização, usando escalas de 7 pontos

Quadro 2 - Novas competências da organização vistas pelos diferentes níveis organizacionais.

\begin{tabular}{|c|c|}
\hline NIVEL & COMPETÊNCIAS ORGANIZACIONAIS \\
\hline Diretores & $\begin{array}{l}\text { - Experiência de mercado } \\
\text { - Pensamento global } \\
\text { - Capacidade de selecionar tecnologia apropriada } \\
\text { - Capacidade de trabalhar com preços competitivos } \\
\text { - Capacidade de trazer profissionais com diferentes tipos de visão }\end{array}$ \\
\hline Gerentes & $\begin{array}{l}\text { - Conhecimento de mercado e de como fazer o mercado fluir (interferir no mercado) } \\
\text { - Capacidade para atrair administradores que entendem do negócio e do mercado } \\
\text { - Velocidade e flexibilidade } \\
\text { - Conhecimento da tecnologia de informação } \\
\text { - Capacidade de planejamento estratégico } \\
\text { - Capacidade de entrosar a estrutura com as exigências de mercado } \\
\text { - Capadade de motivar as pessoas a trabalhar }\end{array}$ \\
\hline Coordenadores & $\begin{array}{l}\text { - Capacidade de tomar decisões rápidas } \\
\text { - Capacidade de oferecer soluções customizadas } \\
\text { - Qualidade dos serviços } \\
\text { - Foco nos resultados } \\
\text { - Preços competitivos } \\
\text { - Capacidade para transformação e reposição rápidas }\end{array}$ \\
\hline Supervisores & $\begin{array}{l}\text { - Entendimento do mercado presente e futuro } \\
\text { - Capacidade para entender a competição } \\
\text { - Conhecimento tecnológico refinado } \\
\text { - Capacidade de introduzir novos produtos e antecipar necessidades dos clientes } \\
\text { - Pessoal bem treinado } \\
\text { - Capacidade de valorizar os recursos humanos } \\
\text { - Capacidade de alavancagem financeira } \\
\text { - Concepção rápida de projetos }\end{array}$ \\
\hline
\end{tabular}


que variaram de -3 para uma redução considerável a +3 para um aumento considerável em cada variável, com o zero indicando nenhuma mudança.

Verificou-seque a Telemig aumentou sua ênfase em programas de gestão do conhecimento e de gestão de qualidade total depois da privatização, mas os de reengenharia aumentaram em menor extensão. Quanto aos métodos e sistemas utilizados para promover a aprendizagem organizacional, constatou-se que a empresa deu uma ênfase substancialmente maior às atividades dirigidas para três áreas principais: (1) integração interna (projetos de demonstração para promover o uso de equipes multifuncionais, um uso maior dos programas para promover padrões comunse
0 aumento do uso da rede interna de tecnologia de informação), (2) sensibilidade ao mercado (mais atenção ao feedback dos clientes e ao contato mais direto com eles), e (3) o uso de contratados externos e de parcerias (uso de consultores de universidades e de outros especial istas, serviços contratados de outras companhias, políticas para transferência de conhecimento, aprendizagem com outras companhias, edesenvolvimento de alianças estratégicas). Todas as três iniciativas de aprendizagem para a integração interna, a sensibilidade ao mercado e o uso de contratados externos representaram mudanças da antiga cultura da Telemig como uma grande burocracia auto-suficiente do Estado que contava com sua própria geração de conhecimento, principalmente por um

Quadro 3 - Competências pessoais e relacionadas ao trabalho percebidas pelo respectivo nível.

\begin{tabular}{|c|c|c|}
\hline \multirow[t]{2}{*}{ NÍVEL } & \multicolumn{2}{|c|}{ COMPETENNCIAS ORGANIZACIONAIS } \\
\hline & SABER FAZER & SABER SER \\
\hline Diretores & $\begin{array}{l}\text { - Conhecimento de tecnologia e do negócio } \\
\text { - Conhecimento da tecnologia de informação } \\
\text { - Habilidade em no mínimo três idiomas } \\
\text { - Capacidade de visão ampla } \\
\text { - Entendimento do futuro } \\
\text { - Entendimento de tecnologia de ponta } \\
\text { - Capacidade de trazer novos conhecimentos para } \\
\text { a organização }\end{array}$ & $\begin{array}{l}\text { Gerência Multifacetada } \\
\text { - Capacidade de aprender } \\
\text { - Proatividade } \\
\text { - Ecletismo } \\
\text { - Adaptabilidade } \\
\text { - Mente aberta } \\
\text { - Habilidade de negociação }\end{array}$ \\
\hline Gerentes & $\begin{array}{l}\text { - Conhecimento de comunicação de marketing, de } \\
\text { economia, de tecnologia da informação, de pla- } \\
\text { nejamento e do negócio } \\
\text { - Formação em Engenharia } \\
\text { - Avaliação de projetos } \\
\text { - Saber como escolher seus subordinados } \\
\text { - Conhecimento de diferentes línguas } \\
\text { - Experiência em telecomunicações }\end{array}$ & $\begin{array}{l}\text { - Habilidades interpessoais } \\
\text { - Capacidade de trabalhar sob pressão } \\
\text { - Adaptabilidade } \\
\text { - Ter "os pés no chão" } \\
\text { - Saber ouvir } \\
\text { - Habilidades de negociação } \\
\text { - Flexibilidade } \\
\text { - Capacidade para aprendizagem contínua } \\
\text { - Proatividade } \\
\text { - Capacidade de resolver problemas }\end{array}$ \\
\hline Coordenadores & $\begin{array}{l}\text { - Conhecimento técnico } \\
\text { - Capacidade para avaliar cenários } \\
\text { - Conhecimento sobre mercado e finanças } \\
\text { - Saber como lidar com pessoas } \\
\text { - Trabalhar e saber organizar trabalho em equipe } \\
\text { - Motivar pessoas } \\
\text { - Equilíbrio emocional } \\
\text { - Visão holítisca da organização }\end{array}$ & $\begin{array}{l}\text { - Aceitação de mudanças } \\
\text { - Confiança } \\
\text { - Respeito pelas pessoas } \\
\text { - Aprender a cada experiência } \\
\text { - Manter a calma e o bom humor } \\
\text { - Não sofrer com mudanças da companhia } \\
\text { - Criatividade } \\
\text { - Capacidade de aprendizagem contínua }\end{array}$ \\
\hline Supervisores & $\begin{array}{l}\text { - Visão de mercado } \\
\text { - Conhecimento de tecnologia de informação } \\
\text { - Conhecimento de RH } \\
\text { - Saber como operar novas tecnologias } \\
\text { - Conhecimento de contabilidade e orçamento } \\
\text { - Visão sistêmica da organização }\end{array}$ & $\begin{array}{l}\text { - Saber ouvir } \\
\text { - Iniciativa } \\
\text { - Perspicácia } \\
\text { - Autoconfiança } \\
\text { - Flexibilidade } \\
\text { - Sensibilidade }\end{array}$ \\
\hline
\end{tabular}


status elevado e por uma função relativamente autônoma de engenharia de telecomunicações.

0 investimento da empresa na aprendizagem organizacional nos anos que se seguiram à privatização produziu resultados positivos. Houve um aumento relatado nas competências organizacionais, especialmente naquelas que eram consistentes com a implementação de sua transformação em uma firma privada e orientada para o mercado. Verificou-se que a empresa tinha adquirido substancialmente mais competências em capacidade de empreender, habilidades para se adaptar a mudanças e enfraquecimento de limites funcionais internos anteriores, por meio do trabal ho em equipe e inovação.

A aplicação de princípios neo-liberais, incentivando a competitividade e a agilidade da empresa, não foi confinada aos atributos da organização como um todo. Também exigia mudanças complementares para melhorar a contribuição de empregados individuais, inclusive fazê-los mais autoconfiantes. A equipe de funcionários interpretou o investimento da Telemig em aprendizagem organizacional como significando que a companhia requereu tais mudanças nas qualidades eno conhecimento que trouxeram a seus trabal hos. De acordo com avaliações dos respondentes a respeito das qualidades e das habilidades pessoais que a empresa requereu deles desde sua privatização, estão colocadas no topo da lista as habilidades de adaptar-se a situações novas, lidar com a incerteza, negociar, lidar com o estresse, lidar com o conflito, ser flexível, trabal har em equipes, eser criativo. Estas são todas as qualidades e habilidades orientadas para a adaptação e a inovação organizacional, e e empresa requereu de sua equipe de funcionários maior comprometimento com a mudança organizacional. Ainda que não ao mesmo tempo, estes atributos refletem um custo pessoal para o empregado. Refletem a tensão colocada em indivíduos pelas novas políticas corporativas, tais como 0 estresse e a necessidade de controlar o conflito, que passaram a ser qualidades exigidas pela empresa. São também atributos do empregado que foi "renovado" para tornar-se mais "empregável" no mercado de trabal ho externo e, portanto, mais fácil de despedir se a empresa realizasse 0 downsizing - como de fato o fez. Alguns dos investimentos da Telemig na aprendizagem foram orientados para fornecer uma base para o enfraquecimento potencial do contrato de emprego em suas formas explícitas e implícitas, o que fez com que o programa de aprendizagem da companhia facilitasse a ruptura da confiança.

\section{Aprendizagem e ruptura de confiança}

Como Sisson (1994) indicou, organizações não demitem mais empregados, elas "diminuem de tamanho"; elas não controlam empregados, elas "conferem poder". Gestão da qualidadetotal e reengenharia atualmentesignificam "fazer mais com menos". A privatização da Telemig mudou não somente o contrato de emprego, mas tudo que havia conferido a ela suas características como empresa boa para setrabal har. Como uma organização do Estado ela tinha fornecido segurança no emprego, e foi considerada como uma família e como uma mãe por causa dos benefícios que concedeu. Os empregados sentiam orgulho da atmosfera amigável da organização. A Telemig era uma empresa que tinha uma reputação por seus serviços e pela qualidade de seus profissionais.

Os empregados não podiam compreender por que a ênfase anterior em uma carreira interna era substituída no discurso da administração superior pelas possibilidades de construir uma carreira fora da empresa. Identificaram o que Ihes pareceram ser inconsistências nas políticas da administração. Um gerentedenível médio mencionou: "esta nova equação não se enquadra. A companhia tem reduzido 0 número dos empregados, cortado o pagamento de horas extras e aumentado a quantidade de trabalho para os empregados significativamente". Pareceu inconsistente mudar os laços simbólicos que eram fonte de identificação com a companhia. Os gerentes se referiram a uma substancial redução de poder e autonomia em favor da matriz como a "domesticação da Telemig", e como "o efeito da vaca leiteira", para indicar que fornecia recursos humanos qualificados às outras empresas do grupo. Um gerente descreveu a organização como "o retrato na parede". Como ele disse:

“a Telemig foi boa enquanto durou. É um retrato na parede da qual guardamos memórias agradáveis. Para todos nós, significou que estávamos protegidos. A mudança foi tão drástica que os empregados a comparam com uma situação em que você entra em uma companhia e sai de outra".

Embora a noção da ruptura de confiança tenha sido tratada na literatura primeiramente como uma interrupção nas dimensões implícitas do contrato de emprego, o estudo de caso da Telemig mostra que de fato impactou outras dimensões al ém da econômica, tais como os laços cognitivos, emocionais e sociais que os empregados tinham para com a organização. Sugere que a ruptura de confiança envolveu também uma privação dos sinais simbólicos que fizeram da Telemig uma líder no setor. As entrevistas com os gerentes em particular sugerem o ressentimento contra a organização que removeu os símbolos que tinham dado à Telemig um status distinto dentro de seu setor. A ruptura de confiança depois da privatização feriu a auto-estima dos empregados. Um gerente se referiu a isto da seguinte maneira: 
"Hoje há uma ferida em nossa auto-estima. As pessoas ressentem a organização enxuta que foi criada em conseqüência da privatização". De acordo com um outro gerente, "as melhores 'cabeças' foram transferidas para o escritório central, e aqueles que permaneceram ficaram ressentidos por não terem sido escolhidos para serem transferidos". Um terceiro gerente disse que "a redução da autonomia representa uma punição à região [Minas Gerais] e aos nossos clientes". Outro pensamento é quea centralização depois da privatização "está matando a criatividade, a iniciativa e o sentido das pessoas de realização".

Mais importante, a mudança da propriedade implicou um rearranjo das relações da companhia com suas partes interessadas, que levaram a ajustes radicais em suas regras de emprego. Esta pode ter sido a razão mais importante para a ruptura de confiança que se seguiu à privatização. 0 rearranjo nas relações com as partes interessadas provocou uma comparação do sistema de contribuição e de redistribuição no qual se considerava que os administradores e os empregados contribuíam mais e obtinham um menor retorno. A nova administração superior justificou a redistribuição defendendo a idéia de que "espera-se que os subordinados façam mais para a companhia do que ela faz por eles, o oposto do que acontecia quando a Tel emig era uma organização estatal". O u como um gerente observou "ninguém deve adotar a posição de que é obrigação da organização fornecer os meios para o desenvolvimento dos empregados; nós temos que fazer isto nós mesmos".

\section{DISCUSSÃO}

0 caso da Telemig ilustra como a ideologia pode ser uma ferramenta que reconcilia a aprendizagem dos membros de uma organização com a chamada "organização de aprendizagem". Ou seja, mostra como os programas educacionais da administração foram projetados intencionalmente para mudar a mentalidade dos empregad os e criar novas competências que combinariam com o novo perfil organizacional que pretendiam construir. Empregados mais flexíveis, mais adaptáveis e pró-ativos combinariam com uma organização mais flexível, mais adaptável e pró-ativa. Os atributos de membros individuais deveriam ser os mesmos daqueles da organização, ou ao menos, ser complementares.

O neoliberalismo ajudou a pôr estas mudanças no contexto; forneceu uma justificativa para elas em níveis individual eorganizacional euma estrutura queintegrou uma "identidade ideal do trabalho" (Alvesson e Willmott, 2002) com um tipo ideal de organização. Além disso, ajudou a apresentar a mudança como inevitável. A globalização e a abertura dos mercados foram retratadas como eventos que estão afetando as pessoas em toda parte. A situação era de fragilidade das organizações ao enfrentar a hiper-competição que caracterizava o setor. As firmas contratam, mudam de local e de propriedade em um ritmo mais rápido a fim de lidar com a crescente incerteza ambiental. A lógica por trás deste tipo de ambienterequereu um perfil diferentedeempregado. Ou seja, uma pessoa mais adaptável equenão veja a organização apenas como um meio de sobrevivência econômica e fonte de satisfação pessoal. A nova administração desta maneira trabalhou para uma separação entre a identidade pessoal e os novos atributos organizacionais. 0 contexto amigável, familiar e particularista promovido anteriormente pela organização deveria ser substituído por outro que enfatizasse o individual ismo ea consciência de custo. A autoconfiança ea autonomia deveriam ser incentivadas como atributos individuais consistentes com a cultura neoliberal da empresa (Hellas e Morris, 1992). Supôs-se que este tipo de mentalidade não somente eximiria a organização de suas responsabilidades anteriores com seus empregados, mas serviria também para incentivar os indivíduos a encontrar suas próprias alternativas, investindo em sua instrução e desenvolvimento.

Os programas de aprendizagem iniciados pela companhia serviram para apresentar os ideai s neoliberais sob uma luz positiva. Discursos de liberação e de auto-realização geralmente apresentam as mudanças de maneira sedutora para assegurar o compromisso com os objetivos da administração e uma transição organizacional tranqüila e sem resistência (Alvesson e Willmott, 2002). Os termos usados na Telemig, tal como o empowerment, a liderança de equipe e a coordenação de projetos, difundem uma imagem positiva da organização para seus empregados, ao mesmo tempo em que suas conotações emancipatórias desencorajam a resistência organizada.

A ideologia foi também uma ferramenta para preparar os empregados para a ruptura de confiança que iria acompanhar a mudança da propriedade. Com a privatização os novos proprietários eram isentos da obrigação de manter o contrato social que tinha prevalecido sob a propriedade do Estado. Desta maneira, a nova administração esperava mais esforço dos empregados, sem a garantia de segurança de emprego. $\mathrm{Na}$ Telemig, os empregados perceberam a contradição entre esperar lealdade à organização e ao mesmo tempo negar a base para a identificação com ela. Requereu a leal dade dos empregados sem oferecer-Ihes uma responsabilidade correspondente. A seus olhos, a companhia quis receber sem oferecer nada em troca.

A ruptura de confiança não obstante teve um impacto muito maior. Além de afetar o contrato de emprego, minou as bases para a identidade dos empregados. As mudanças 
queforam introduzidas ameaçaram o status, o poder eo prestígio dos empregados. Por exemplo, vários gerentes e engenheiros foram dispersos pelas subsidiárias em diferentes partes do país. Muitos daqueles que não perderam seus empregos tiveram sua posição reduzida de gerentes a meros coordenadores de projeto - uma mudança que substituiu o salário fixo pelo variável e assim aumentou a incerteza pessoal. Esta transformação foi vista como uma mudança da imagem da organização zelosa e maternal. Assim, o estudo corrobora 0 argumento de que a identidade éum dos al vos dos programas de aprendizagem que são projetados para assegurar aos empregados conformidade e controle administrativo.

\section{Implicações}

Grande parte da literatura supõe que a apren dizagem organizacional éuniversalmente benéfica e, conseqüentemente, um bem social. 0 conhecimento é pretensamente civilizador e enriquecedor; portanto o investimento na criação organizacional do conhecimento pela aprendizagem éjustificado como uma coisa positiva. 0 problema desta visão é que supõe uma unidade deentendimento ede final idadeentretodos os membros da organização sobre a natureza e a função da aprendizagem. 0 exemplo da Telemig demonstra claramente que este não é necessariamente 0 caso. Por esta razão juntamonos a outros ao argumentar quea aprendizagem organizacional - a aquisição de competências e de conhecimento disponíveis em uma organização - somentepodeocorrer por meio de aprendizagem nas organizações. 0 foco exclusivo na aprendizagem organizacional conduz a uma reificação que obscurece diferenças cognitivas intergrupos e conflitos de interesse (Villinger, 1996; Gherardi e Nicolini, 2001). A experiência da Telemig indica que aprendizagem dentro de uma organização pode ser promovida para favorecer os interesses de algumas partes interessadas à custa de outras. Permitindo que o "esforço de negociação" (Behrend, 1957) seja redefinido contra os interesses dos empregados, a aprendizagem transforma-se em um instrumento de política organizacional. Conseqüentemente, não é interpretada à mesma luz, nem é aceita igualmente por todos os membros de uma organização; el a é contestada.

0 estudo elaborou e ilustrou o conceito de "aprendizagem contestada". Este conceito necessita ser incorporado à teoria da aprendizagem nas organizações por diversas razões. Primeiramente, dá atenção a um aspecto válido das relações organizacionais que é geral mente negligenciado na discussão sobre aprendizagem. Este aspecto é capturado na tensão entre as perspectivas dos acionistas e dos stakeholders na governança corporativa. O neoliberal ismo injetou o sistema de val ores do acionista em programas de privatização. 0 val or do acionista é usado para justificar 0 investimento em aprendizagem nas organizações do modo como a Telemig fez, porque tal investimento está entre os ativos intangíveis que podem aumentar o retorno do capital dos acionistas. A perspectiva do stakeholder, pelo contrário, chamaria a atenção para os custos e benefícios a outros grupos que têm interesse na firma e que participaram de contratos implícitos com ela.

Uma segunda razão para empregar o conceito da aprendizagem contestada é que lançando as bases da contestação, expande-se a teoria da aprendizagem nas organizações pela incorporação a ela das forças ideológicas e materiais que informam edirigem um programa particular deapren dizagem. Desta maneira, fornece-se a chave para a análise política da aprendizagem nas organizações do tipo apresentado neste artigo. A reestruturação corporativa tem mais do que nunca sido conduzida de uma maneira não-participativa, com anúncios unilaterais de mudanças que ameaçam os interesses do empregado (Cascio, 2002). Os programas de aprendizagem iniciados para apoiar este tipo de reestruturação inevitavelmente terão um significado político. Contextualizar a aprendizagem nas organizações levando em conta as forças ideológicas e materiais conduz, entretanto, a uma interpretação significativamente diferente daquela aprendizagem.

U ma terceira consideração é associada à observação de que os investimentos organizacionais na aprendizagem podem não alcançar as expectativas de que ela funcione como meio de melhorar a competitividade das empresas por causa das resistências que podem ser encontradas. Uma perspectiva política da aprendizagem pode ajudar a identificar as fontes de tal resistência e as razões para ela, abrindo assim a porta para os administradores oferecerem garantias de que seus contratos implícitos com a equipe e os empregados não serão minados pela ruptura de confiança.

Finalmente, uma considerável significação está sendo conferida à confiança nas organizações como um fator que motiva não somente o comprometimento com os objetivos organizacionais, mas reduz também os custos de transação. A possibilidade de que os programas de aprendizagem nas organizações possam preparar terreno para uma ruptura dessa confiança não tem sido considerada e merece mais atenção no futuro. Pois quando a aprendizagem nas organizações é associada com a ruptura de confiança, a visão positiva de que a aprendizagem conduz à emancipação pessoal não pode ser sustentada.

\section{Artigo Convidado. Aprovado em 12.11.2003.}

\section{Referências Bibliográficas}

ALVESSON, M.; WILLMOTT, H. Making sense of management: A critical analysis. London: Sage, 1996. 
ALVESSON, M.; WILLMOTT, H. Identity regulation as organizational control: Producing the appropriate individual. Journal of Management Studies, v. 39, n. 5, p. 619-644, 2002.

BARTLETT, C. A.; GOSHAL, S. The myth of the generic manager: New personal competencies for new management roles. California $M$ anagement Review, v. 40, n. 1, p. 93-116, 1997.

BEHREND, H. The effort-bargain. Industrial and Labor Relations Review, v. 10, n. 4, p. 503-515, 1957.

BERGER, P. L.; LUCKMANN, T. The social construction of reality. London: Allen Lane; The Penguin Press, 1966.

BLAIR, M. Ownership and control: Rethinking corporate governance for the twenty-first century. Washington, DC: The Brookings Institution, 1995.

BLAIR, M. (ed.). Wealth creation and wealth sharing: A colloquium on corporate governance and investments in human capital. Washington, DC: The Brookings Institution, 1996.

BOSCHI, R.; DINIZ, E.; SANTOS F. Elites políticas e econômicas no Brasil contemporâneo. São Paulo: Fundação Konrad Adeneur, 2000.

BOWMAN, E.; SINGH H.; USEEM, M.; BHADURY R. When does restructuring improve economic performance? California Management Review, v. 41, n. 2, p. 33-55, 1999.

BROWN, A. D.; STARKEY, K. Organizational identity and learning: A psychodynamic perspective. Academy of Management Review, v. 25, n. 1, p.102-20, 2000.

CARRIERI, A. 0 fim do "mundo Telemig": A transformação das significações culturais em uma empresa de telecomunicações. 2001. Tese (Doutorado em Administração de Empresas) - Cepead/FACE/UFMG, Minas Gerais, 2001.

CASCIO, W.F. Responsible restructuring. San Francisco: Berrett-Koehler, 2002.

CARRIER, J. M eanings of the market. Oxford: Berg, 1997.

CHILD, J. Organization: a guide to problems and practice. London: Harper \& Row, 1984.

CHILD, J. Theorizing about organization cross-nationally. Advances in Comparative International Management, n. 13, p. 75, 2000.

CHILD, J.; LOVERIDGE, R. Information technology in European services. Oxford: Blackwell, 1990.

CHILD J.; HEAVENS, S. The social constitution of organizations and its implications for organizational learning. In: DIERKES, M.; ANTAL, A.; CHILD, J.; N ONAKA, I. (eds.). Handbook of learning and knowledge. Oxford: Oxford University Press, p. 308-326, 2001.

CHILD J.; RODRIGUES, S. B. Repairing the breach of trust in corporate governance. Corporate Governance: An international review, 2003a. No prelo.

CHILD, J.; RODRIGUES, S. B. Social identity and organizational learning. In: EASTERBY-SMITH, M.; LYLES, M. A. (eds.). Handbook of organizational learning and knowledge management. Oxford: Blackwell: p. 535-556, 2003b.

COLLINSON, D. Managing the shopfloor: Subjectivity, masculinity and workplace culture. Berlin: Walter de Gruyter, 1992.

CORLEY K.; GIOIA, D. Semantic learning as change enabler: Relating organizational identity and organizational learning. In: EASTERBY-SMITH, M.; LYLES, M.A. (eds.). Handbook of organizational learning and knowledge management. Oxford: Blackwell, p. 623-638, 2003.

DEAKIN, S.; HOBBS, R.; NASH, D.; SLINGER, G. Implicit contracts, takeovers and corporate governance: In the shadow of the city code. ESRC Centre for Business Research, University of Cambridge, December, 2002 (Working Paper 254).
DOZ, Y. Managing core competency for corporate renewal: towards a managerial theory of core competencies. In: CAMPBELL, A.; LUCHS, K. (eds.). Core competency-based strategy. Boston: International Thompson Business Press, 1997.

FEAR, J. R. Thinking historically about organizational learning. In: DIERKES, M.; ANTAL, A.; CHILD, J.; NONAKA, I. (eds.) Handbook of organizational learning and knowledge. Oxford: Oxford University Press: $p$. 162-191, 2001.

FIOL, C. M.; LYLES, M. A. Organizational learning. Academy of M anagement Review, v. 10, n. 4, p. 803-813, 1985.

FRIEDMAN, M. Capitalism and freedom. Chicago: Chicago University Press, 1962.

GHERARDI S.; NICOLINI, D. The sociological foundations of organizational learning. In: DIERKES, M.; ANTAL, A.; CHILD, J.; NONAKA, I. (eds.). Handbook of learning and knowledge. Oxford: Oxford University Press, p. 35-60. 2001.

HAMEL G.; PRAHALAD C. K. Competing for the future. Boston, MA: Harvard Business School Press. 1994.

HAYEK VON, F. A. The constitution of liberty. London: Routledge, 1960.

HELLER, F.; PUSIC, E.; STRAUSS, G.; WILPERT, B. Organizational participation: Myth and reality. Oxford: Oxford University Press, 1998.

HEELAS P.; MORRIS, P. The values of the enterprise culture. London: Routledge, 1992.

KELLEY, J. Rethinking industrial relations. London: Routledge, 1998.

KNIGHTS D.; WILLMOTT, H. Organizational culture as management strategy: A critique and illustration from the financial services industry. International Studies of M anagement and Organization, n. 17, p. 40-63, 1987.

LAPALOMBARA J. The underestimated contributions of political science to organizational learning. In: DIERKES, M.; ANTAL, A.; CHILD, J.; NONAKA, I. (eds.). Handbook of learning and knowledge. Oxford: Oxford University Press, p. 137-161, 2001.

LE BOTERF, G. Dela competence: Essai sur un attracteur étrange. Paris: Les Éditions d' Organisation, 1997.

LITTLER, C. R.; SALAMAN, G. Bravermania and beyond: Recent theories of the labour process. Sociology, v. 16, n. 2, p. 251-269, 1982.

LITTLER, C.R. Comparing the downsizing experiences of three countries: A restructuring cycle? In:'BURKE, R. J.; COOPER, C. L. (eds.) The organization in crisis. Oxford: Blackwell, p. 58-77, 2000.

LUZ, T. Telemar-M inas: Competências que marcam a diferença. 2001. Tese (Doutorado em Administração) - Cepead/FACE/UFMG, Minas Gerais, 2001.

MARCH, J. G.; SIMON, H. A.-Organizations. New York: Wiley, 1958.

MARCH, J.G.; OLSEN, J.P. Ambiguity and choice in organizations. Bergen: Universitets Fralaget, 1976.

MARQUAND, D. The enterprise culture: Old wine in new bottles? In: HELLAS, P.; MORRIS, P. (eds.). The values of the enterprise culture. London: Routledge, p.61-72, 1992.

MERKENSH., GEPPERT, M.; ANTAL, A. Triggers of organizational learning during the transformation process in central european countries. In: DIERKES, M., ANTAL, A., CHILD, J.; NONAKA, l. (eds.) Handbook of organizational learning and knowledge. Oxford: Oxford University Press, $p$. 242-263. 2001.

NONAKA, I.; TAKEUCHI, H. The knowledge-creating company. New York: Oxford University Press, 1995. 
OSTERMAN, P. Securing prosperity. Princeton, NJ: Princeton University Press, 1999.

PETTIGREW, A.M. On studying organizational culture. Administrative Science Quarterly, v. 24, n. 4, p. 570-581, 1979.

PETTIGREW, A. M. The awakening giant: Continuity and change in $\mathrm{ICl}$. Oxford: Blackwell, 1987.

PIRES, J. C. Políticas regulatórias no setor de telecomunicações: A experiência internacional e o caso brasileiro. Rio de Janeiro: BNDES, 1999. (Textos para Discussão n.71).

POPPER, KARL R. The open society and its enemies. London: Routledge; Kegan Paul, 4th edition, 1962.

PRAHALAD, C. K.; HAMEL, G. The core competences of the corporation. Harvard Business Review, v. 68, n. 3, p. 68-79, 1990.

RAY, C.A. Corporate culture: The last frontier of control? Journal of Management Studies, v. 23, n. 3, p.287-297, 1986.

RHINESMITH, S. H. Guia gerencial para a globalização. Rio de Janeiro: Berkeley, 1993.

RODRIGUES, S.B. The political and institutional dynamics of culture change. Birmingham: Birmingham Business School, 2003. (Working Paper).

RODRIGUES, S.B.; CHILD, J. The dynamics of identity construction and deconstruction. Birmingham: Birmingham Business School, 2003a (Working Paper).

RODRIGUES, S.B.; CHILD, J. Co-evolution in an institutionalized environment. Journal of M anagement Studies, 2003b. No prelo.

ROSE, N. Governing the enterprising self. In: HELLAS, P.; MORRIS, P. (eds.). The values of the enterprise culture. London: Routledge, p.141-164, 1992.
ROSENSTIEL VON, L.; KOCH, S. Change in socioeconomic values as trigger of organizational learning. In: DIERKES, M.; ANTAL, A.; CHILD, J.; NONAKA, I. (eds.). Handbook of organizational learning and knowledge. Oxford: Oxford University Press, p. 198-220, 2001.

SENGE, P. Through the eye of the needle. In: GIBSON, R. (ed.). Rethinking the future. London: Nicholas Brealey, p.123-145, 1997.

SHLEIFER, A.; SUMMERS, L.H. Breach of trust in hostile takeovers. In: AUERBACH, A. J. (ed.). Corporate takeovers: Causes and consequences. Chicago: University of Chicago Press, 1988.

SIMONS, T.; IN GRAM, P. Organization and ideology: Kibbutzim and hired labour, 1951-1965. Administrative Science Quarterly, v. 42, n. 4, p.784814, 1997.

SISSON, K. In search of HRM. British Journal of Industrial Relations, v. 31, n. 2, p. 201-210, 1994.

SKIN NER, B.F. About behaviourism. New York: Knopf, 1974.

SUTHERLAND, P. Cognitive development today: Piaget and his critic. London: Paul Chapman, 1992.

TAJFEL, H. (ed.). Social identity and group relations. Cambridge: Cambridge University Press, 1982.

THOMPSON, G.; MCHUGH, D. Work organizations. New York: Palgrave, 2002.

VILLINGER, R. Post-acquisition managerial learning in central Eastern Europe. Organization Studies, v. 17, n. 2, p. 181-206, 1996.

WEICK, K. Sense making in organizations. Thousand Oaks, CA: Sage, 1995.

WESTON F.; SIU, J.; JOHNSON B. Takeovers restructuring $\&$ corporate governance. N ew Jersey: Prentice Hall, 2001.

\section{Suzana B. Rodrigues}

Professora titular do Cepead-UFMG e Senior Research Fellow da Birmingham Business School, UK. Co-diretora do Mestrado em Negócios Internacionais e Co-diretora do CIBOR - Centre for International Management and Organization Research Birmingham University. PhD pela University of Bradford - Management Center. Interesses de pesquisa em negócios internacionais, alianças estratégicas e organizações.

E-mail: s.b.rodrigues@bham.ac.uk

Endereço: Birmingham Business School, University of Birmingham. Birmingham B15 2T, UK.

\section{John Child}

Professor de Negócios Internacionais e Organizações da Birmingham Business School , UK. Co-diretor do Mestrado em Negócios Internacionais e Co-diretor do CIBOR - Centre for International Management and Organization Research Birmingham University. Ph.D. em administração pela University of Cambridge. Interesses de pesquisa em alianças estratégicas, aprendizagem organizacional e evolução de novas formas organizacionais.

E-mail: j.child@bham.ac.uk

Endereço: Birmingham Business School, University of Birmingham. Birmingham B15 2T, UK.

\section{Talita R. Luz}

Professora do Cepead-UFMG e da Faculdade Novos Horizontes. Interesses de pesquisa em competências gerenciais e organizacionais, aprendizagem organizacional e organizações.

E-mail tarluz@brree.com.br

Endereço: Rua Alvarenga Peixoto, 1270 - Bairro Santo Agostinho, Belo Horizonte - MG, 30180-121. 